\title{
A Probabilistic Predictive Model for Residential Mobility in Australia
}

\author{
M. Namazi-Rad ${ }^{\mathrm{a}^{*}}$ \\ N. Shukla ${ }^{a}$ \\ A. Munoz \\ P. Mokhtarian ${ }^{\mathrm{c}}$ \\ J. $\mathrm{Ma}^{\mathrm{a}}$
}

\begin{abstract}
Household relocation modelling is an integral part of the planning process as residential movements influence the demand for community facilities and services. Department of Families, Housing, Community Services and Indigenous Affairs (FaHCSIA) created the Household, Income and Labour Dynamics in Australia (HILDA) program to collect reliable longitudinal data on family and household dynamics. Socio-demographic information (such as general health situation and well-being, lifestyle changes, residential mobility, income and welfare dynamics, and labour market dynamics) is collected from the sampled individuals and households. The data shows that approximately 17\% of Australian households and $13 \%$ of couple families in the HILDA sample relocate residence each year. Yet, little is known on how this information can be utilised to develop a predictive model of household relocation. This study links changes in employment status and household types to a reliable estimate of the residential relocation probability by developing a Logit model to explain the residential relocation in Sydney metropolitan area using the HILDA dataset.
\end{abstract}

\section{Key words: HILDA; Household Relocation Modelling; Logit Model.}

\section{Introduction}

Household residential relocations are individual decisions that are influenced by and affect community makeup, and population levels in different ways across countries. Where populations choose to reside increases the uncertainty of public policy upon future government services demands. This uncertainty also decreases the reliability of traditional equilibrium based approaches to modelling population movements. Changes in household configurations, individual attributes, and community structures have strong influences on the quality and types of services governments are required to provide. Thus, planners are under increasing pressure to

\footnotetext{
${ }^{a}$ SMART Infrastructure Facility, University of Wollongong, Wollongong, NSW 2522, Australia,

${ }^{\mathrm{b}}$ School of Management and Marketing, University of Wollongong, Wollongong, NSW, 2522, Australia

${ }^{c}$ School of Mathematics and Statistics, University of Wollongong, Wollongong, NSW 2522, Australia

*Corresponding author: Mohammad-Reza Namazi-Rad mohammad_namazi@uow.edu.au http://dx.doi.org/10.14453/isngi2013.proc.33
} 
develop robust policies that govern which area receives what services and why. Traditionally, residential relocation has been modelled using aggregate forecasting techniques. However, the assumptions supporting these models can fail to apply to specific socio-demographic segments of a population, increasing the need to adopt more sophisticated, robust planning tools based on peer-reviewed research. Research developments are plentiful in areas such as social psychology ${ }^{1-}$ ${ }^{2}$, demography ${ }^{3}$, epidemiology ${ }^{4}$ and other social and behavioural sciences ${ }^{5-7}$. Robust models of residential relocation have the power to incorporate the more important factors that influence a geographical area's popular perception and value of available services.

Models of relocation typically require region-specific attributes to be well incorporated as cultural and local geography factors play a significant role in relocation decisions ${ }^{8}$. Examples include tenure at the current residential location and the perceived net benefit of relocation. In order to measure existing individual perceptions of social and environmental elements, NamaziRad et al. ${ }^{9}$ grouped attributes of interest to the target population to six factors describing various aspects of liveability perception. The work yielded a linear additive model to calculate reliable estimates of area-specific liveability indices. The model used a Computer Assisted Telephone Interviewing (CATI) conducted in Sydney by the SMART Infrastructure Facility. The study also linked perceived liveability with residential relocation decisions at the household level. The intention being to provide a singular predicted state based on an analytical model and necessary assumptions to ensure, tractability. These assumptions typically include the treatment of populations as homogenous non-autonomous individuals, a contentious assumption as individual households are typically autonomous decision makers. To address the issue, new models must consider the households as individual autonomous entities, capable of evaluating and processing available information into preferences and instantiate relocation decisions if required. The premise that individual entity choice is the required output of the model necessitates a rethinking of how planners perceive the populations affected by implemented policies from traditional econometric equilibrium modelling views of populations as aggregations of homogenous individuals, to that of populations as a collective of autonomous, heterogeneous entities.

\section{Modelling area-specific residential mobility based on HILDA}

Economic modelling has arguably been the only conceptually consistent and analytically tractable framework to model residential relocation dynamics. In the urban economics context, a willingness-to-pay driven framework relies on five axioms that to provide its consistency ${ }^{10}$ : (1) prices adjust to achieve local equilibrium, (2) self-reinforcing effects generate extreme outcomes, (3) externalities cause inefficiency, (4) production is subject to economies of scale and (5) competition generates zero economic profit. This approach has been criticised by its reductionism, supported by arguments that residential relocation choices encompass factors like social bonding or 'sense of place' that can hardly fit into a single currency framework. Moreover, assumptions of perfect competition, economies of scale, and equilibrium markets tend to reduce the validity of conclusions inferred from such models. Louviere and Meyer ${ }^{11}$ proposed to forge a better alliance between economic theories and behavioural research in order to improve our representation of informal choices within a discrete choice-modelling paradigm. A common methodology used in discrete choice modelling is Logit class models, whereby a number of alternatives are evaluated by the probability of each alternative being chosen by an individual autonomous entity. 
This study will address the problem of modelling residential re-location using a Logit class model. The model estimates the probability of a household choosing to relocate and implicitly initiating the relocation process. Attributes contributing to the relocation decision include changes to number of bedrooms required, employment status and income situation, household configuration and tenure. The dataset used for the relocation choice model comes from the Australian Government Department of Families, Housing, Community Services and Indigenous Affairs (FaHCSIA). FaHCSIA initiated the HILDA program to gather reliable longitudinal data on family and household dynamics. Socio-demographic information (such as general health situation and well-being, long term lifestyle changes, residential mobility, income and welfare dynamics, and labour market dynamics) is collected from the sampled individuals and households. The Melbourne Institute of Applied Economic and Social Research currently manage the HILDA project and the data repository.

Cursory data analysis indicates that around $17 \%$ of the total households and $13 \%$ of couple families in the HILDA sample relocate each year. Further analysis conducted shown in Figure 1, presenting the proportion of residential relocations in a year in Australian major metropolitan areas from 2001 to 2011. There are noticeable fluctuations in area-specific movements. For example, the proportion of movements in Darwin peaks in 2004-2005, perhaps due to the major development project initiatives in Darwin at the time: redevelopment of the Wharf Precinct and associated new housing developments, including Outrigger Pandanas and Evolution on Gardiner $^{12}$. For Tasmania ${ }^{13}$, the influence of permanent migrants during 2004-2005 represented a significant increase of 141 residents from 2003-2004, and 278 more people than in 2002-2003.

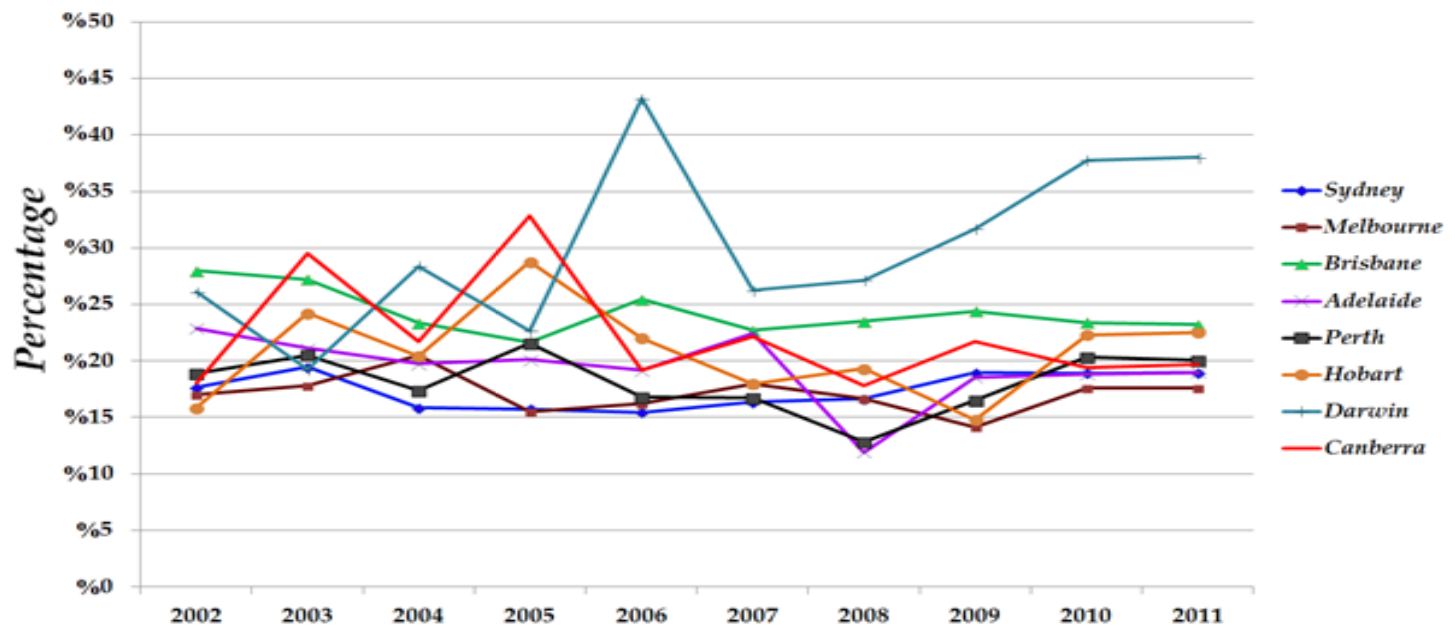

Figure 1.Self-reported movements within the Australian large cities 
The decrease in Canberra residents between 2003 and 2004 may be due to bushfire events. In January 2003 severe weather triggered catastrophic bushfires that destroyed around 500 homes. In reaction to the disaster, the Canberra Spatial Plan for the city's future development was released in 2004. Plans included a new Canberra district to be situated west of Lake Burley Griffin as initiatives to foster commercial and residential growth. Although the number of residential movements at the Australian major metropolitan areas has fluctuated from 2002 to 2011, on average the proportion of total households moved was between 17\% and 23\% in 2011 except Darwin for which this proportion was approximately closer to 38\%. Other objective and subjective factors not captured in this study would undoubtedly influence movements in different parts of Australia. The cursory analysis presented on Figure 1 represents some of the qualitative assessments of the model of residential relocation choice methodology will attempt to formalize.

\section{Residential location choice methodology}

The purpose of this study is to determine if and when a household (at the Sydney metropolitan area) initiates the relocation process. It is assumed that all households are able to initiate the relocation process, whether the relevant conditions sufficiently necessitate the initiation of the process is the result of the model. For example, a household may be in a situation whereby a change in job location may require a longer commute, prompting a greater possibility of initiating the relocation process to reduce commute time. The increased commute time will translate to an increase in their willingness to relocate. However, if the change in job is not sufficient enough to initiate the trigger, the household will not initiate the relocation process. The attributes used for relocation choice trigger (for $i$ th household) include:

- $\Delta \mathrm{E}_{i}$ : Change in job/income status for $i$ th household from time $t$ to $t-1$,

- $\Delta \mathrm{HH}_{i}$ : Household configuration change from time $\mathrm{t}$ to $t-1$ and,

- $\quad \mathrm{T}_{\mathrm{i}}$ : Tenure of $j$ th household at time $t$.

The concept of household configuration change is represented as a function of the supply and demand number of bedrooms in the dwelling occupied by the household. The existing number of bedrooms represents the supply while the number of individuals in the household, and their household relationship determines demand. If the demand exceeds the supply, then the household will be more inclined to relocate, and vice versa. The formula is presented as follows:

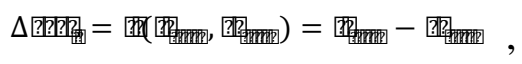

where $S_{\text {bed }}$ is the number of bedrooms in the current dwelling, and $D_{b e d}$ is the number of bedrooms required by household $\mathrm{j}$. The number of bedrooms required by a household is a function of the number of adults (as couples) that are able to share a bedroom, and the number of children in the household (with provisions made for their age). Children over the age of 10 and relatives do not share a bedroom. Figure 2 illustrates the process of calculating a household's demand for bedrooms. 


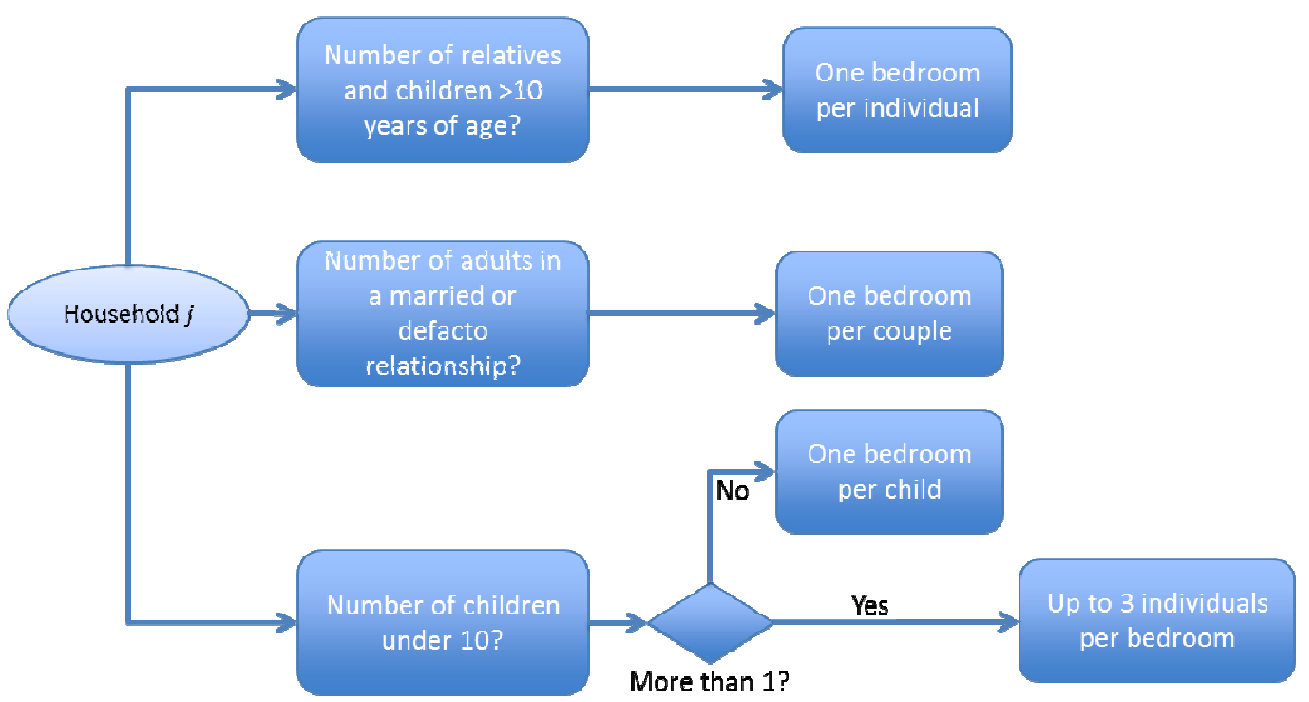

Figure 2. Bedroom demand calculation.

In situations where couples are married or de facto, or there are 2 or more children under 10 , a room can be shared (to a maximum of 3 individuals per room). All other situations require that every individual in a household have a bedroom. Room stress or crowding in households has been the topic of little research in the academic literature. Typically, researchers have produced heuristic models that round out the number of bedrooms occupied by a household (or household level bedroom demand) by simplified means. One such example is the Equivalised Crowding Index method espoused by New Zealand residential planning authorities ${ }^{14}$, a linearized model of crowding in households used in population statistics of housing adequacy.

For the ith household at the HILDA data (for the Sydney metropolitan area), the probability of an active location choice trigger ' ' within a year is modelled through a generalized linear model (GLM) as follows ${ }^{15}$ :

where is the linear predictor and is modelled by the inverse logistic link function:

-

Here, the model intercept is denoted by , while and are the model coefficients. Using the HILDA available for 5774 households living at least for a year at the Sydney areas from 2001 to 2011, model coefficients are estimated using the Maximum Likelihood method. The results are presented in Table 1.

Table 1. Model parameter estimates

\begin{tabular}{|l|c|c|c|}
\hline Model Covariates & $\begin{array}{l}\text { Associated } \\
\text { Coefficient }\end{array}$ & S.E. & Significance \\
\hline Intercept & $\mathbf{0 . 6 2 3}$ & $\mathbf{0 . 0 6 0 2 4 7}$ & $<0.001$ \\
\hline $\begin{array}{l}\text { Change in income } \\
(\quad)\end{array}$ & $\mathbf{= - \mathbf { 0 . 0 0 0 1 2 5 }}$ & $\mathbf{3 . 8 1}$ & \\
\hline $\begin{array}{l}\text { Household } \\
\text { configuration } \\
\text { change }\end{array}$ & $\mathbf{- \mathbf { 0 . 0 6 8 7 4 }}$ & $\mathbf{0 . 0 3 4 1 0 7}$ & $\mathbf{0 . 0 4 3}$ \\
\hline Tenure & $\mathbf{= - \mathbf { 0 . 5 7 6 6 }}$ & $\mathbf{0 . 0 1 4 2 0 4}$ & $<\mathbf{0 . 0 0 1}$ \\
\hline
\end{tabular}




\section{Discussion}

Household relocation modelling is an integral part of the planning process as household locations determine demand for community facilities and services. The household relocation choice is important to assess the impact of migration among various metropolitan areas on the urban landscape. Thus, it is essential for planners to have a deep understanding of the impact changes in planning policy have on urban dynamics. Residential mobility is a process that has traditionally been modelled using aggregate forecasting that often provides a singular predicted state based on a certain statistical model and related assumptions. Given these conditions, this study developed a model that represents residential relocation choices autonomously at the household level.

Population modelling predicted a continuing trend of rapid urbanisation in 2007 and owing to the increasing population in Australia ${ }^{16}$ with an estimated urban growth rate of $1.49 \%$ between 2010-2015. The Australian population is accustomed to high levels of wellbeing and quality of life and affords them the opportunity to live well. A valid evaluation of location-based human activities is required for urban designers and planners to make effective planning and appropriate decisions policy decisions that influence for maintaining and improving the quality of urban environments. It is critical for state and local governments, in developing and implementing long term land use master plans, to provide and maintain a series of benchmarks that measure the performance of urban environments and demonstrate a clear commitment to current and future residents. Such planning decisions require the capacity to assess and compare the impact of competing land use policies and infrastructure development. This research used a nominal Logit model to estimate the residential location choices of the population in Sydney Metropolitan Area. The main attributes of this model are change in household income, household configuration change, and the tenure of the household. HILDA data for 2001-2011 was used to estimate the coefficients in the Logit model. This model, validated against existing datasets, provides some indication that choice modelling is an appropriate means of modelling the autonomous nature of relocation choices made by households. How these choices affect the overall urban landscape is a product of a number of other interactions that are part of a larger research effort. However, the validity in the findings presented in this paper provide some guidance as to what predictive modelling tools can be integrated with other tools to provide the deeper understanding required for effective policy design.

In the analysis of data presented in Figure 1, it is expected that factors not captured in this study would undoubtedly cause movements in different parts of Australia. Using more accurate, and perhaps more sophisticated models, to further explore into the link between catastrophic events or government-driven redevelopment initiatives provides an exciting future research direction for this work.

\section{References}

${ }^{1}$ Sampson, R.J., "Linking the Micro- and Macrolevel Dimensions of Community Social Organization," Social Forces, Vol. 70, 1991, pp. 43-64. http://dx.doi.org/10.1093/sf/70.1.43 
${ }^{2}$ Oishi, S., and Schimmack, U., "Residential Mobility, Well-Being, and Mortality," Journal of Personality and Social Psychology, Vol. 98, No 6, 2010, pp. 980-994. http://dx.doi.org/10.1037/a0019389

${ }^{3}$ South, S.J., and Crowder, K.D., "Residential Mobility Between Cities and Suburbs: Race, Suburbanization, and Back-To-The-City Moves," Demography, Vol. 34, 1997, pp. 525-538. http://dx.doi.org/10.2307/3038307

${ }^{4}$ Jelleyman, T., and Spencer, N., "Residential Mobility in Childhood and Health Outcomes: A Systematic Review," Journal of Epidemiology and Community Health, Vol. 62, 2008, pp. 584-592. http://dx.doi.org/10.1136/jech.2007.060103

${ }^{5}$ Wood, D., Halfon, N., Scarlata, D., Newacheck, P., and Nessim, S., "Impact of Family Relocation on Children's Growth, Development, School Function, and Behavior," Journal of the American Medical Association, Vol. 270, 1993, pp. 1334-1338. http://dx.doi.org/10.1001/jama.1993.03510110074035

${ }^{6}$ Tucker, C.J., Marx, J., and Long, L., "Moving on: Residential Mobility and Children's School Lives," Journal of Educational Sociology, Vol. 71, 1998, pp. 111-129. http://dx.doi.org/10.2307/2673244

${ }^{7}$ Sergeant, J.F., Ekerdt, D.J., and Chapin, R., "Measurement of Late-Life Residential Relocation: Why Are Rates for Such a Manifest Event so Varied?" Journals of Gerontology: Series B: Psychological Sciences and Social Sciences, Vol. 63B, 2008, S92-S98. http://dx.doi.org/10.1093/geronb/63.2.S92

${ }^{8} \mathrm{Hu}$, W., Cox, L. J., Wright, J., and Harris, T. R., "Understanding Firms' Relocation and Expansion Decisions Using Self-Reported Factor Importance Rating," The Review of Regional Studies 2008, Vol. 38, No. 1, 2008, pp. 67-88.

${ }^{9}$ Namazi-Rad, M., Perez, P., Berryman, M., and Lamy, F., "An experimental determination of perceived liveability in Sydney," ACSPRI Conferences, RC33 Eighth International Conference on Social Science Methodology, 2012, pp. 1-13.

${ }^{10}$ O'Sullivan A., Urban Economics, 7th edition, McGraw-Hill International Edition, 2009, p. 466.

${ }^{11}$ Louviere, J.J., and Meyer, R.J., "Formal Choice Models of Informal Choices: What Choice Modeling Research Can (and Can't) Learn from Behavioral Theory," Review of Marketing Research, Vol. 4, 2008, pp. 3-32. http://dx.doi.org/10.1108/S1548-6435(2008)0000004005

${ }^{12}$ Northern Territory Government, Darwin City Waterfront, archived from the original on 4 June 2007. Retrieved 13 May 2007.

${ }^{13}$ Minnucci, C., Community Profile 2007, Hobart City Council, 2008.

${ }^{14}$ Statistics New Zealand, Housing Quality Statistics, (accessed on 13th of February, 2013).

${ }^{15}$ Train, K., Discrete Choice Methods with Simulation, Cambridge University Press, 2009.

${ }^{16}$ Population Division of the Department of Economic and Social Affairs of the United Nations Secretariat, World Population Prospects: The 2010 Revision and World Urbanization Prospects: The 2011 Revision, Wednesday, February 20, 2013. 